\title{
Self-medication practices among health care professionals in a Private University, Malaysia
}

\author{
*Abdul Nazer Ali, Jason Tiong Kion Kai, Choo Chun Keat, SA Dhanaraj \\ Faculty of Pharmacy, AIMST University, 08100 Bedong, Kedah Darul Aman, Malaysia
}

\begin{abstract}
The purpose of this study was to evaluate and analyze the prevalence of self-medication practice among healthcare professionals in a private university, Malaysia. Prospective, quantitative, cross-sectional design which attempts to measure the self-medication practices among the teaching healthcare personnel through questionnaire survey form, self-developed and pre-validated consisting of open and closed-ended questions. Among respondents, 77.6\% were practicing self medication. The reasons were, familiar with treatment options $(23.5 \%)$ and mild illness $(20 \%)$ and the highest practicing respondents were 30-39 years (76.3\%). The reason among those who did not practice selfmedication was risk of adverse reactions (31.6\%). Self-medication practice was more prevalent among medical professionals $(86.5 \%)$ followed by pharmacy and dentistry $(70 \%)$. Headache $(15.7 \%)$, cough and cold (15\%) among illness and analgesics (13.1\%) and antipyretic (12.7\%) among drugs induced most respondents to practice selfmedication. This study reveals very high prevalence of self-medication practice among healthcare professionals in the local private university. Exposure to drugs, knowledge of their illness and treatment choice remains main contributors. The healthcare professionals must be encouraged to enter the patient role.
\end{abstract}

Key Words: Self-medication, health care professionals, University, prevalence.

\section{INTRODUCTION}

In recent years there has been an increasing trend in self-medication with non-prescription [over-thecounter (OTC)] drugs available in pharmacies and retail outlets. In current days, more drugs were changed from prescription-only medications (POM) to pharmacy medications (Bond, 2001). According to World Medical Association (WMA), POM refer to those drugs which are only available on prescription as they are not safe except under the supervision of a physician because of toxicity and potential harmful effects (Blenkinsopp et al., 1996). The World Self-Medication Industry (WSMI) defines selfmedication as the treatment of common health problems with medicines especially designed, labeled and approved for use without medical supervision (Self medication principles, WSMI).

\footnotetext{
*Corresponding Author:

Abdul Nazer Ali, Associate Professor

Faculty of Pharmacy, AIMST University

Semeling, 08100, Bedong

Kedah Darul Aman, Malaysia

E-mail: abdul.nazerali16@gmail.com

Contact No.: +60103730262
}

Thus self-medication can be defined as obtaining and consuming drugs without the advice of a physician either for diagnosis, treatment or monitoring (Montastruc et al., 1997). Although OTC drugs are meant for self-medication and are of proven efficacy and safety, improper use or abuse may lead to serious consequences, especially in pediatrics, geriatrics, pregnancy and lactation (Murray and Callahan, 2003; Choonara et al., 1996). According to the self-medication hypothesis $(\mathrm{SMH})$, the individual's choice of a particular drug is psychological as in condition when alcohol or other mind-altering drugs used to self-medicate depression (Kasten, 1999).

There is no sector in the healthcare community which is immune to drug abuse/misuse of which the worst offenders include physicians and pharmacists (Dabney, 2001). Most often, physicians find it difficult to enter the patient role due to various reasons such as restricted time, nature of illness, concerns about confidentiality, high ego, etc. Both, ease of access to medications and high drug knowledge, potentially contribute to self-medication among pharmacists (Balbisi et al., 2005) Several 
studies indicated substantial levels of illegal drug use among practicing pharmacists (Gallegos, 1998 and McAuliffe et al., 1987). The prevalence of selfmedication practices is alarmingly high in healthcare professionals $(\mathrm{HCP})$, despite knowing the consequences and potential risks (Rosen et al, 2000). The increased self-medication trend is not only observed in countries with advanced economies but also in developing countries (Shankar et al., 2002).

Several tips have also been suggested by Tannyth and Jacqueline that all consumers should have some basic knowledge about medications in order to conduct self-medication more effectively and safely (Menton and Schoor, 2005). Some examples of conditions where self-medication is appropriate are colds, flu, sore throat, sunburn etc. On the other hand, circumstances that favor physicians' consultations are: symptoms that persist for more than seven days; pregnant, breast-feeding, geriatric or pediatric; the condition has become worse; patient who experience unwanted side effects; possible abuse of medicine; patient have concurrent health issues.

The impact of the problem of self-medication practices among HCP is severe. The consequences of inappropriate self-medication among HCP have been found to have severe implications including legal, ethical, health defects, negative impacts on patient and quality of health care delivery. Like any other person, HCP should also be encouraged through appropriate provision to enter the patient role. This is the only potential solution to decrease the high prevalence of self-medication among HCP. Various studies have shown significant statistics on the enormity of self-medication. In U.S., the prevalence of self-medication is $39 \%$ to $99 \%$ among doctors, in UK 90\%, whereas in Australia 90\%, though believed that it is acceptable to self-medicate for acute illness.

\section{METHODS}

The prospective, quantitative, cross-sectional study was designed in such a way that, it attempts to measure the self-medication practices among the teaching HCP in AIMST University through the use of a questionnaire survey form, self-developed, prevalidated consisting both open and closed-ended questions, and the data generated was analyzed using Statistical Package for Social Sciences (SPSS $®$ ) version 15.
Table 1: Demographic characteristics of the participants.

\begin{tabular}{lcc}
\hline Variable & Frequency & Percentage \\
\hline Age & 9 & \\
$20-29$ & 38 & 10.6 \\
$30-39$ & 14 & 14.7 \\
$40-49$ & 8 & 9.4 \\
$50-59$ & 16 & 18.8 \\
$\geq 60$ & & \\
Sex & 52 & 61.2 \\
$\quad$ Male & 33 & 38.8 \\
Female & & \\
Field of profession & 37 & 43.5 \\
$\quad$ Medicine & 10 & 11.8 \\
Dentistry & 20 & 23.5 \\
Pharmacy & 18 & 21.2 \\
$\quad$ Others & & \\
Level of professional qualification & 8 & 9.4 \\
Graduate & 61 & 71.8 \\
Post Graduate & 16 & 18.8 \\
$\quad$ Doctorate & & \\
Professional experience & & \\
$\quad$ 09 years & 31 & 36.5 \\
10-19 years & 24 & 28.2 \\
20-29 years & 9 & 10.6 \\
30-39 years & 11 & 12.9 \\
$\geq 40$ years & 10 & 11.8 \\
\hline
\end{tabular}

Potential respondents, included in the study were the academic staffs of AIMST University specialized in any healthcare fields. Temporary academic staff respondent, who lost contact during follow-up and incomplete data forms were excluded from this study. This study was conducted between February and April 2011 for a period of three months. About 100 questionnaires were distributed, out of which 85 were completed and retrieved from respondents.

\section{Ethical Considerations}

Careful consideration was given to ethical issues in the design of the study. The objective of the study was explained and confidentiality ensured to the participants along with a written informed consent form.

\section{RESULTS}

The questionnaire has been organized under the following five major sections:

\section{Demographic characteristics of the respondents}

The demographic variables include age, gender distribution, field of profession, level of qualification, and professional experience (Table 1). Out of the total 85 participants, $61.2 \%$ were male and the 
Table 2: Basic conceptual understanding about the term of self-medication.

\begin{tabular}{lcc}
\hline Understanding of self-medication & Frequency & Percentage \\
\hline $\begin{array}{l}\text { Use of drugs (including alcohol) for } \\
\text { relief from any underlying disorder } \\
\text { or condition that results in addiction }\end{array}$ & 18 & 9.3 \\
$\begin{array}{l}\text { The consumption of drugs without } \\
\text { physician's advice to compensate any } \\
\text { medical or psychological condition }\end{array}$ & 28 & 14.4 \\
$\begin{array}{l}\text { Medication of oneself without } \\
\text { professional supervision so as to } \\
\text { alleviate an illness or a condition }\end{array}$ & 39 & 20.1 \\
$\begin{array}{l}\text { Medication of oneself without } \\
\text { prescription for both prescription and } \\
\text { non prescription medications }\end{array}$ & 27 & 13.9 \\
$\begin{array}{l}\text { Use of medication by individuals to } \\
\text { treat self recognized illness or } \\
\text { symptoms }\end{array}$ & 44 & 22.7 \\
$\begin{array}{l}\text { Consumption of OTC medications for } \\
\text { underlying disease }\end{array}$ & 18 & 9.3 \\
$\begin{array}{l}\text { Consumption of any alternative } \\
\text { medicines (Herbal, Chinese etc.) }\end{array}$ & 20 & 10.3 \\
\begin{tabular}{l} 
Total responses \\
\hline
\end{tabular} & $\mathbf{1 9 4}$ & $\mathbf{1 0 0 . 0}$ \\
\hline
\end{tabular}

rest, $38.8 \%$ were female. It was also found that $10.6 \%$ were between the age group of $20-29$ years, $44.7 \%$ were between $30-39$ years, $16.5 \%$ were between 40 - 59 years and $18.8 \%$ were $\geq 60$ years.

With regards to the field of profession, it was found that $43.5 \%$ were from medicine, $23.5 \%$ from pharmacy, $11.8 \%$ from dentistry and $21.2 \%$ were from other fields (nursing, physiotherapy, microbiology and biochemistry etc). It was further found that 9.4\% were graduates, $71.8 \%$ were post-graduates, and $18.8 \%$ were doctorates. It was also observed that $36.5 \%$ of participants had less than 10 years, followed by $28.2 \%$ with 10 to 19 years, $10.6 \%$ with 20 to 29 years, $12.9 \%$ with 30 to 39 years and $11.8 \%$ had more than 40 years of professional experience.

\section{Understanding and personal perception towards self-medication}

Basic conceptual understanding about the concept of self-medication among the participants is important to assess the extent and predisposing factors for self-medication. A total of 194 responses were recorded out of which $22.7 \%$ perceived selfmedication as use of medications to treat selfrecognized illnesses/symptoms and $20.1 \%$ consi- dered self-medication as medication of oneself without professional (Table 2).

\section{Reasons for self medication practices}

By knowing the extent of understanding and personal perception of $\mathrm{HCP}$ on self-medication practice, varied responses of health seeking behavior and self-medication practices observed among the respondents were further analyzed to investigate the self-medication practices among HCP. Among the total respondents, $77.6 \%$ admitted that they practice self-medication whereas only $22.4 \%$ denied. Predisposing factors for self-medication practices were also assessed. The respondents had the option to indicate more than one reason that predisposes them to self-medication (Table 3).

$23.5 \%$ responses registered for 'familiarity with treatment options'. Next in order was $20.0 \%$ due to 'mild illness'. The respondents who stated that they 'do not have a primary physician nearby' were $3.0 \%$. A few respondents stated that they do not practice self-medication and their reasons were also assessed. The results show $31.6 \%$ of the respondents stated that the 'risk of adverse drug reactions' as the main reason, $23.7 \%$ stated 'risk of wrong diagnosis' and $2.6 \%$ cited other reasons. In line with further investigation, the first line of action they take when fallen ill was also assessed. Among them, 68.4\% responded as consulting a physician nearby, $21.1 \%$ responded as consult a specialist and $10.5 \%$ responded as no action taken. The frequency of seeking medical advice in non self-medicating respondents was found to be $63.2 \%$.

\section{Comparison of self-medication practice using the demographic factors}

The study found it relevant to establish a comparison between demographic variables and self-medication practices among respondents. The results in table 4 show that $76.3 \%$ in the age group of $30-39$ years recorded the highest frequency for self-medication whereas $23.7 \%$ indicated they do not practice. In the age group $\geq 60$ years, $81.3 \%$ indicated of selfmedication practices while $18.7 \%$ indicated that they do not practice. Among the least frequency recorded in the age group of $50-59$ years, $87.5 \%$ recorded selfmedication practice but $12.5 \%$ indicated that they do not practice. On the whole it was observed from the entire sample size, $77.6 \%$ indicated self-medication 
Table 3: Practice of self medication.

\begin{tabular}{|c|c|c|}
\hline Variable & Frequency & Percentage \\
\hline \multicolumn{3}{|l|}{ Responses for self medication practice } \\
\hline Yes & 66 & 77.6 \\
\hline No & 19 & 22.4 \\
\hline \multicolumn{3}{|l|}{ Reasons for practicing self medication } \\
\hline Economical cost & 20 & 10.0 \\
\hline Time saving & 29 & 14.5 \\
\hline Mind illness & 40 & 20.0 \\
\hline Privacy & 9 & 4.5 \\
\hline Familiar with treatment options & 47 & 23.5 \\
\hline Quick relief & 22 & 11.0 \\
\hline No primary physician near by & 6 & 3.0 \\
\hline Condition do not merit seeing physician & 22 & 11.0 \\
\hline Others & 5 & 2.5 \\
\hline \multicolumn{3}{|l|}{$\begin{array}{l}\text { Reasons for NOT practicing self } \\
\text { medication }\end{array}$} \\
\hline Risk of using wrong drugs & 8 & 21.1 \\
\hline Risk of adverse drug reactions & 12 & 31.6 \\
\hline Risk of wrong diagnosis & 9 & 23.7 \\
\hline Risk of wrong use of drugs & 8 & 21.1 \\
\hline Others & 1 & 2.6 \\
\hline \multicolumn{3}{|l|}{$\begin{array}{l}\text { First action when ill (non-practicing } \\
\text { respondents) }\end{array}$} \\
\hline Consult a GP nearby & 13 & 68.4 \\
\hline Consult a specialist & 4 & 21.1 \\
\hline No action & 2 & 10.5 \\
\hline \multicolumn{3}{|l|}{$\begin{array}{l}\text { Medical advice received in the past } 3 \\
\text { years }\end{array}$} \\
\hline Yes & 12 & 63.2 \\
\hline No & 7 & 36.8 \\
\hline
\end{tabular}

practices whereas only $22.4 \%$ said they do not practice self-medication. There was no significant difference between the self-medication practices and the age group of respondents $(p=0.609)$. The gender distribution of self-medication practices among respondents was established and the results show that $77.6 \%$ practice self-medication whereas $22.4 \%$ do not practice. Of those who self-medicate, $60.67 \%$ were found to be males and $30.34 \%$ were females. Even though there were more male respondents who practice self-medication when compared to females, the difference in the rate of self-medication among male and female was not statistically significant $(\mathrm{p}=$ 0.841) (Table 4).

An establishment of self-medication practices by field of profession was also investigated and the results indicated that, $86.5 \%$ of respondents in medical profession, $70.0 \%$ of dentists and $70.0 \%$ of pharmacists predominantly practice self-medication. Among the others, $72.2 \%$ indicated self-medication practices. Though the rate of self-medication recorded by respondents in medicine field is slightly higher $(86.5 \%)$ than the rest of the fields, the figures appear rather very close $(p=0.394)$. There was no statistical difference in the rate of self-medication practices among respondents with different field of healthcare profession (Table 4).

The study also accessed the practices of selfmedication by level of qualification among the respondents. The highest frequencies of practicing respondents who indicated self-medication was of post-graduate qualification which recorded $80.3 \%$, $68.8 \%$ respondents with doctorate qualification, and $75.0 \%$ were graduates. There is no significance between self-medication practices among respondents with level of qualification $(\mathrm{p}=0.602)$ (Table 4).

The study was also interested in finding out whether the length of professional experience has an influence on self-medication practice among respondents. Among the respondents who practiced self-medication, $80.6 \%$ had professional experience less than 10 years, $75.0 \%$ were $10-19$ years, and $66.7 \%$ were in $20-29$ years experience. There is no significant establishment between the years of professional experience and self-medication practices among respondents $(p=0.751)$ (Table 4$)$.

\section{Illness or indications for self-medication among respondents}

The indications for which the respondents used to self-medicate and the medications used commonly were also assessed. The most common illness for self-medication was headache $(15.7 \%)$; followed by cough and common cold (15.0\%); fever and chill and common flu $(10.6 \%)$; gastric pain and diarrhea $(10.1 \%)$; Allergy $(8.0 \%)$; pains $(6.8 \%)$; constipation (6.1\%); fungal or microbial infections $(4.9 \%)$ and other diseases $(2.1 \%)$. The types of medications (drugs) used in self-medication practice among the respondents were also recorded. The most common class of drugs used was found to be analgesics $(13.1 \%)$; anti-pyretic (12.7\%); anti-inflammatory (9.9\%); anti-histamines (9.7\%); antacids (9.6\%); energy supplements such as vitamins and minerals (8.6\%); topical applications which include antifungal, anti-microbial and analgesics (7.9\%); antibiotics $(6.7 \%)$; nasal or ear/eye drops $(5.2 \%)$; laxatives (4.1\%); traditional medicines $(2.1 \%)$; 
Table 4: Comparison of self medication Practice.

\begin{tabular}{|c|c|c|c|c|}
\hline \multirow[t]{3}{*}{ Variables } & \multicolumn{4}{|c|}{ Self Medication } \\
\hline & \multicolumn{2}{|c|}{ Yes } & \multicolumn{2}{|c|}{ No } \\
\hline & Frequency & Percentage & Frequency & Percentage \\
\hline \multicolumn{5}{|l|}{ Age } \\
\hline $20-29$ & 8 & 88.9 & 1 & 11.1 \\
\hline $30-39$ & 29 & 76.3 & 9 & 23.7 \\
\hline $40-49$ & 9 & 64.3 & 5 & 35.7 \\
\hline $50-59$ & 7 & 87.5 & 1 & 12.5 \\
\hline$\geq 60$ & 13 & 81.3 & 3 & 18.7 \\
\hline \multicolumn{5}{|l|}{ Sex } \\
\hline Male & 40 & 76.9 & 12 & 23.1 \\
\hline Female & 26 & 78.8 & 7 & 21.2 \\
\hline \multicolumn{5}{|l|}{ Field of profession } \\
\hline Medicine & 32 & 86.5 & 5 & 13.5 \\
\hline Dentistry & 7 & 70.0 & 3 & 30.0 \\
\hline Pharmacy & 14 & 70.0 & 6 & 30.0 \\
\hline Others & 13 & 72.8 & 5 & 31.3 \\
\hline \multicolumn{5}{|c|}{ Level of qualification } \\
\hline Graduate & 6 & 75.0 & 2 & 25.0 \\
\hline Post Graduate & 49 & 80.3 & 12 & 19.7 \\
\hline Doctorate & 11 & 68.8 & 5 & 31.3 \\
\hline \multicolumn{5}{|c|}{ Professional experience } \\
\hline$\leq$ 09years & 25 & 80.6 & 6 & 19.4 \\
\hline 10-19 years & 18 & 75.0 & 6 & 25.0 \\
\hline 20-29 years & 6 & 66.7 & 3 & 33.3 \\
\hline $30-39$ years & 8 & 72.7 & 3 & 27.3 \\
\hline$\geq 40$ years & 9 & 90.0 & 1 & 10.0 \\
\hline
\end{tabular}

corticosteroids such as anti-asthmatics (7.0\%); and oral contraceptives (1.9\%) (Table 5).

\section{Opinions and feedbacks about self-medication practices among the participants}

The study also included a major section to investigate the respondent's personal opinion in the factors preventing them from seeking health care from physicians as first line of action during illness. The opinions that are reported by the respondents include familiarity of common ailments; economical cost of self-medication; lack of time due to busy working schedule preventing physician visits; easy access to medications; mild illness that does not merit seeing a physician; no physician nearby and over-confidence in drug knowledge and treatment options possessed by the HCP.

\section{DISCUSSION}

In this study, the prevalence of self-medication among 85 HCP (medicine, dentistry, pharmacy, etc.) in AIMST University, Malaysia was investigated. Among the respondents who practiced selfmedication, the highest $(76.3 \%)$ were aged between $30-39$ years and the least $(8.2 \%)$ were aged between $50-59$ years. From the irregularity between the age distribution of respondents and the prevalence rate of self-medication, shows clearly that there is no significant association between the age of respondents and prevalence of self-medication.

Gender distribution of respondents showed that $61.2 \%$ were males while the rest, $38.8 \%$ were females. Shankar et al. (2002) and Parimi et al. (2002) also supported the findings in this study that gender was not significantly associated with selfmedication. However, the results contradict with findings observed by Rosen et al., and Sexton that female HCP were more susceptible to selfmedication due to strenuous job requirement (Shankar et al., 2002 and Sexton, 2003). Figueiras and Caamano (2000) reported different results that more frequent self-medication among female was due to 
Table 5: Illness (indications) and medications for selfmedication.

\begin{tabular}{|c|c|c|}
\hline Variable & Frequency & Percentage \\
\hline \multicolumn{3}{|c|}{ Illness (indications) for self-medication } \\
\hline Headache & 67 & 15.7 \\
\hline Cough and common cold & 64 & 15.0 \\
\hline Fever and chills & 45 & 10.6 \\
\hline Common flu & 45 & 10.6 \\
\hline Gastric pain & 43 & 10.1 \\
\hline Allergy & 34 & 8.0 \\
\hline Diarrhea & 43 & 10.1 \\
\hline Constipation & 26 & 6.1 \\
\hline Pain & 29 & 6.8 \\
\hline Fungal/Microbial infections & 21 & 4.9 \\
\hline Others & 9 & 2.1 \\
\hline Total responses & 426 & 100 \\
\hline \multicolumn{3}{|l|}{$\begin{array}{l}\text { Medications (drugs) used for self- } \\
\text { medication }\end{array}$} \\
\hline Analgesics & 70 & 13.1 \\
\hline Anti-inflammatory & 53 & 9.9 \\
\hline Anti-pyretics & 68 & 12.7 \\
\hline Anti-histamines & 52 & 9.7 \\
\hline Antacids & 51 & 9.6 \\
\hline Laxatives & 22 & 4.1 \\
\hline Oral contraceptives & 10 & 1.9 \\
\hline Antibiotics & 36 & 6.7 \\
\hline Corticosteroids & 4 & 7.0 \\
\hline Nasal/Ear/Eye drops & 28 & 5.2 \\
\hline Topical applications (antifun- & 42 & 7.9 \\
\hline \multicolumn{3}{|l|}{ gals/analgesics etc.) } \\
\hline Nutritional supplements & 39 & 7.3 \\
\hline Energy supplements (Vita- & 46 & 8.6 \\
\hline \multicolumn{3}{|l|}{ mins/Minerals etc.) } \\
\hline Traditional medicines & 11 & 2.1 \\
\hline Others & 2 & 4.0 \\
\hline Total responses & 534 & 100 \\
\hline
\end{tabular}

the fact that they usually seek health services more frequently and take better care of them.

The study recorded a very high rate of selfmedication practices among HCP which accounted to $86.5 \%$ in medicine, followed by $70.0 \%$ from pharmacy and dentistry. The studies of Kriegler et al., Dabney and Hollinger provide empirical evidence in support of this claim (Dabney et al., 1999 and Kriegler et al., 1994). However there are study outcomes reported which favor pharmacists as the prime runners for self medication practices. These variations may have been the result of methodological differences. This finding is in consonance with what has been generally observed in the selfmedication among HCP literature.
It was observed from this study that physicians recorded a slightly higher prevalence rate of selfmedication practices $(86.5 \%)$ compared to the other HCP. However, Dorcas noted that the selfmedication rates among pharmacists $(88 \%)$ and physicians $(86 \%)$ were not statistically different. Whereas, Kenna and Wood recorded a prevalence rate of $58.7 \%$ among pharmacists, McAuliffe noted a similar rate $59 \%$ among physicians and Christie et al., observed a $52 \%$ rate among physicians (McAuliffe et al., 1987, Kenna et al., 2004 and Christie et al., 1998). High prevalence rate of self-medication among physicians is commonly due to their personal perception and mindset. Based on Davidson et al., high numbers of physicians think that it was acceptable to self-medicate for acute or chronic illnesses (Davidson et al., 2003). Furthermore, Chamber also noted that physicians are more likely to treat themselves (Chamber, 1993).

Impressive knowledge about drugs and treatment options also strongly contribute to the fact that physicians and pharmacists are among the highest respondents who practice self-medication in this study. Balbisi and Ambiza revealed that pharmacists and physicians are among the $\mathrm{HCP}$ with the greatest access to medications and have impressive knowledge of prescription drugs and their use in the treatment of various drug therapies which increase the potential of self-medication (Balbisi et al., 2005).

In this study, among level of qualification, the highest prevalence of self-medication was recorded among respondents with post-graduate qualification $(71.8 \%)$ while doctorate qualification $(12.9 \%)$ recorded a significantly lower self-medication practice. From this, it is obvious that the level of qualification does not play a significant role in the prevalence rate of self-medication practices among respondents. Unlike the findings from this study, Figueiras et al., and Barros et al., observed that people with higher levels of education tend to selfmedicate more frequently (Figueiras et al., 2000 and Barros et al., 2009). The reasons could be, higher the knowledge about medications, the greater is the feeling of personal autonomy in the face of decisions about their own health. Also the level of qualification is directly associated with the drug knowledge possessed and the familiarity of treatment options, as observed in this study. Parimi et al., also observed 
that levels of educational qualification was significantly associated with adequate knowledge of treatment options and are likely to self-medicate (Parimi et al., 2002).

This study further indicated that the respondents with more than 40 years of professional experience have the highest prevalence rate of self-medication $(90 \%)$. However, this does not indicate that the prevalence rate of self-medication increases with the increase in the professional experience of respondents. The prevalence rate of respondents with less than 10 years of professional experience recorded $80.6 \%$ and varies in different age group which indicates that there is no significance associated between professional experience and prevalence rate of self-medication practices. Professional experience can also be directly associated with the drug knowledge and familiarity of treatment options. Dorcas and Henry James et al., suggested that higher professional experience will be more likely to contribute to the knowledge of appropriate medication and familiarity of treatments options by the respondents and hence, increase the rate of selfmedication (James et al., 2006). Although professional experience contributes to the likelihood of self-medication, it is not observed in this study. Though the exact rate of self-medication practices is yet to be concluded in different regions, even the most conservative estimates are that at least $8 \%$ to $12 \%$ of physicians will self-prescribe at some point of their career (Brewste, 1986). Talbot et al., also noted that there is no group of HCP that is immune to the risk of self-medication practices (Talbot et al., 1998). The impact of self-medication among HCP will be severe if safety measurements are not taken. Medication misuses associated with self-medication by health care professionals had been shown to be a major risk factor for medical malpractice and negligence, lawsuits along with the development of physical and psychological illnesses (Rivers et al., 1998).

Most of the HCP were hypocrite and self-biased in the practices of self-medication. They believed that they are immune to prescription drug misuses since they had competent knowledge about prescription drugs and their treatment options (Balbisi et al., 2005 and Dabney et al., 1999). The results from this study further supports that as little as $18.0 \%$ of the health care professionals understand that self-medication includes the use of drugs (including alcohol) for relief from any underlying disorder or condition that results in addiction. Brown et al., concluded that the inability of physicians to recognize the signs and symptoms of substance abuse also contributes to adverse risks in self-medication (Brown et al., 1998).

The single most cited factor or reason for the high rate of self-medication among respondents is their knowledge of drugs. This study has equally confirmed this when respondents indicated their familiarity with treatments options (23.5\%), that has been cited among others as the common reason. Indeed, it has been observed that HCP especially physicians and pharmacists have great access to medication as well as their impressive knowledge of drug use as fundamental pointers to the high prevalence rate (Balbisi et al., 2005).

Prior experience and non-seriousness of the illness were the two major reasons of self-medication in this study and both associated with each other. The low severity of symptoms of illness is also frequently reported in literatures and different surveys. As a result of knowledge, the study recorded in its ratings of reason for self medication, which a significant number of respondents, said that their illness is mild $(20.0 \%)$, and $11.0 \%$ stated that their condition does not merit seeing a physician. This means that the respondents have imposed their subjective judgment in determining both their own diagnosis and treatment (Dabney et al., 1999). Issues pertaining to time saving, though the lesser factor recorded in this study $(14.5 \%)$ has also received extensive observation in previous studies. Stoudemire and Rhoades, Allibone et al., Rosen et al., all noted that long working hours are among other factors that predispose these HCP to self-medication (Shankar et al., 2002, Stoudemire et al., 1993 and Allibone et al., 1981).

As observed in this study, headache recorded $15.7 \%$ as the major indication for self-medication followed by $15.0 \%$ cough and common cold, and $10.6 \%$ was fever and chills. Sallam et al., confirmed this by reporting that the most used self-medicating drugs were those drugs for pain relief and respiratory system (Sallam et al., 2009). Association of the European Self-Medication Industry has listed common diseases in self-medication as pain, allergy, 
colds, sore throats, coughs and diarrhea (Guiding Principles in Self-Medication, 1999). OTC drugs such as antacids (9.6\%) and energy supplements $(8.6 \%)$ which include vitamins and minerals both recorded high rates in self-medication. Dabney in his study supported this finding by observing a high rate of OTC drugs $(60 \%)$ in self-medication due to easy availability (Dabney et al., 1999).

This study also observed the involvement of prescription drugs in self-medication practices among HCP although the rate is slightly lower compared to non-prescription drugs. Prescription drug like anti-histamine recorded $9.7 \%$ while antibiotics $6.7 \%$. In concordance to this, Shankar also noted that prescription drugs such as antibiotics were not commonly used in self-medication (Shankar et al., 2002). On the other hand, Dorcas, Hem et al., and Tenaw reported a high rate of antibiotics (84\%) in self-medication practices (Hem et al., 2005 and Tenaw et al., 2004). Sarahroodi et al., and Richman et al., reported the main indication with antibiotics $(73.3 \%)$ was respiratory problems such as common cold and sore throat (Sarahroodi et al., 2009 and Richman et al., 2001). Antibiotics are susceptible to the risks of misuse and yet they are often exposed to the high rate of self-medication practices (Richman et al., 2001). The involvements of antibiotics in self-medication practices among HCP, other than physicians are due to the fact they are the commonly sold medications (Gore et al., 1994). Traditional medicines also represent a mild contribution $(2.1 \%)$ in self-medication among HCP. This further indicates that traditional medicines are starting to make their way into self-medication practices.

\section{CONCLUSION}

The prevalence of self-medication practice among $\mathrm{HCP}$ in the local private university is very high. The HCP like physicians and pharmacists are no exception. The professional exposure to drugs, knowledge of their illness and treatment choice remains as the fundamental contributor to selfmedication practice among HCP. The three main categories of drugs used in self-medication practices include analgesics, antipyretics and antiinflammatory drugs, which are indicated in headache, common cold, fever and chills. In order to curb the spate of self-medication practices among HCP, fundamental policy initiatives are required. Like any other person, the HCP must accept and be encouraged to enter the patient role.

\section{ACKNOWLEDGEMENT}

The authors are thankful to all the respondents who have participated in the study. The authors are also thankful to the management and dean, faculty of Pharmacy, AIMST University, Malaysia for giving consent and support to carry out this work.

\section{REFERENCES}

Allibone. A., Oakes. D., Shannon. H.S. (1981). The Health and Health Care of Doctors. J Roy Col Gen Prac.31:726-734. PMCID: 1972241

Balbisi. E.A., Ambizas. E.M. (2005). Self Prescribing of Non controlled Substances among Pharmacists. Am J Heal Syst Pharm.62:2508-2511. [DOI]

Barros. A.R.R., Griep. R.H., Rotenberg. L. (2009). Selfmedication among nursing workers from public hospitals. Rev. Latino-Am Enfermagem. 17:1015-1022. PMID 20126945

Blenkinsopp, A., Bradley. C. (1996). Patients, society and the increase in self-medication. BMJ. 312:629-632.

Bond, C. (2001). POM To P - Implications for Practice Pharmacists. Prim Care Pharm.2:5-7.

Brewster. J.M. (1986). Prevalence of alcohol and other drug problems among physicians. JAMA. 225:1913-20. [DOI]

Brown. R.L., Fleming. M.F. (1998). Training the trainers; substance abuse screening and Intervention. Int J Med Psyc.28:137-146.

Chamber. R.M. (1993). What Should Doctors Do When They Become Sick. Family Practice.10:416-423. [DOI]

Choonara. I., Gill. A., Nunn. A.(1996). Drug Toxicity and Surveillance in children. Brit J Clin Pharm.42:407-410. [DOI]

Christie. J.D., Rosen. I.M., Bellini. L.M., et al. (1998). Prescription Drug Use and Self-prescription among Resident Physicians. J Amer Med Asso.280:1253-1255. [DOI]

Dabney. D.A., Hollinger. R.C. (1999). Illicit prescription drug use among pharmacists: evidence of a paradox of familiarity. Work and Occupations. 26:77-106. [DOI]

Dabney.D.A. (2001). Onset of Illegal Use of Mind-Altering or Potentially Addictive Prescription Drugs among Pharmacist. J Am Pharm Assoc. 4:392-400. [DOI]

Davidson. S.K., Schattner. P.L. (2003). Doctors' health seeking behavior: a questionnaire survey. Med J Aust.179:302-305. 
Figueiras. A., Caamano. F. (2000). Gestal-Otero.JJ. Sociodemographic factors related to self-medication in Spain. Eur J Epidemio.16:19-26. PMID: 10780338

Gallegos. K.V., Veit. F.W., Wilson. P.O. (1988). Substance abuse among health professionals. Maryland Med J.37:191197.

Gore. P.R., Madhavan. S. (1994). Consumers' preference and willingness to pay for pharmacist counselling for nonprescription medicines. J Clin Phar Thera. 19:17-25. [DOI]

Guiding Principles in Self-Medication. European SelfMedication Industry (AESGP). 1999.

Hem. E., Stokke. G., Tyssen. R., et al. (2005). Self-prescribing among young Norwegian doctors: a nine-year follow-up study of a nationwide sample. BMC Med. 3:16 [DOI]

Kasten. B.P. (1999). Self-Medication with Alcohol and Drugs by Persons with Severe Mental Illness. Ame Psyc Nur Asso.5:80-87. [DOI]

Kenna. G.A., Wood. M.D. (2004). Prescription Subscription Use by Pharmacists and Other Health Professionals. J Ame Pharm Asso. 44:684-693.

Kriegler. K.A., Baldwin. I.N., Scott. D.M. (1994). A survey of alcohol and other drug use behaviours and risk factors in health profession students. J Am Coll Health. 42:259-265. [DOI]

McAuliffe. W.E., Santangelo. S., Magnuson. E. (1987). Risk factors in drug impairment in random samples of physicians and medical students. Int J Addict. 322:825-841. [DOI]

Montastruc. JL., Bagheri. H., Geraud. T., et al.( 1997). Pharmacovigilance of Self- Medication. Therapy vol. 52:195-110. PMID: 9231503

Murray. M.D., Callahan. C.M. (2003). Improving Medication Use for Older Adults: An Integrated Research Agenda. Ann Int Med. 139:2425-2459. PubMed ID: 12965970

Parimi. N., Pinto Pereira. L.M., Prabhakar. P. (2002). The general public's perceptions and use of antimicrobials in Trinidad and Tobago. Rev. Panam Salud Publica. 12:11-18. PMID: 12202020

Richman. P.B., Garra. G., Eskin. B. (2001). Oral antibiotic use without consulting a physician: a Survey of ED patients. Am J Emerg Med. 19:57-60. PMID: 11146021
Rivers. P.A., Bae. S. (1998). Substance abuse and dependence in physicians: detection and treatment. Health. Manpower Manage.24:183-187. PMID: 10346323

Rosen. I.M., Christie. J.D., Bellini. L.M., et al. (2000). Health and Health Care among Housestaff in Four U.S. Internal Medicine Residency Programs. J Gen Int Medi.15:116-121. PMID: 10672115, PMCID:PMC1495333).

Sallam. S.A., Khallafallah. N.M., Ibrahim. N.K., et al. (2009). Pharmacoepidemiological Study of Self-medication in Adults Attending Pharmacies in Alexandria, Egypt. Eas Medi Heal J.15:683-691.

Sarahroodi. S., Arzi. A. (2009). Self-medication with antibiotics. J Biol Sci.9:829-832. [DOI]

Self-medication principles. World Self-Medication Industry (WSMI).

Sexton. R. (2003). Maintaining the Wellbeing of GPs. BMJ.326:S101. PMID:12663427).

Shankar. P.R., Partha. P., Shenoy. N. (2002). Self-medication and Non-doctor Prescription Practices in Pokhara Valley, Western Nepal. A Questionnaire Based Study, BMC. Family Practice.3:17. [DOI]

Sharma. R., Verma. S.H., Kapoor. B. (2005). Self Medication among Urban Population of Jammu City. Ind J Pharm.37:49-43. [DOI]

Stoudemire. A., Rhoads. J.M. (1993). When a doctor needs a doctor; special considerations for the physician patient. Ann Int Med. 98:654-669. PMID: 6846978

Talbott. G.D., Gallegos. K.V., Angres. D.H. (1998). Impairment and recovery in physicians and other health professionals. In: Graham AW, Schultz TK, Wilford BB, editors. Principles of addiction medicine. 2nd ed. Chevy Chase (MD): Amer Soc Addi Med.1263-1280.

Menton, T., Schoor, J.V. (2005) Principles of Self-Medication. S.A pharmacist's assistant January/February. 5-6.

Tenaw. A., Tsige. G.M. (2004). Self-medication practices of drug consumers. Ethiop J Health Sci.14:1-11. 